\title{
Des inhibiteurs de la mort cellulaire : activine, érythropoiétine
}

A côté des facteurs de croissance, qui stimulent les divisions cellulaires, on trouve d'assez nombreux facteurs trophiques dont la présence est indispensable à la survie cellulaire. Le premier et le mieux connu est le NGF (nerve growth factor). Ont ensuite été décrits pour leur rôle sur la survie des cellules nerveuses le FGF (fibroblast growth factor), la purpurine [1], le BDNF (brain derived neurotrophic factor) [2] et le facteur neurotrophique ciliaire [3]. Une équipe du Salk Institute (La Jolla, CA, USA) vient, grâce à l'utilisation d'une lignée nouvelle de cellules de tératome se différenciant dans la voie neuronale sous l'influence de l'acide rétinoïque, de montrer que l'activine pouvait être ajoutée à la liste des facteurs neurotrophiques [4]. La démarche suivie a consisté à rechercher un facteur qui pouvait remplacer l'acide rétinoïque pour éviter la mort des cellules de tératome P19 cultivées en milieu synthétique. L'activine est une molécule dimérique déjà connue (notamment des lecteurs de $\mathrm{m} / \mathrm{s}, n^{\circ} 8$, vol. 2, p. 466) et décrite comme un modulateur d'origine ovarienne de la libération de FSH par l'hypophyse. Par ailleurs, l'érythropoïétine est connue comme la cytokine de stimulation de l'érythropoiièse. Elle agit au niveau des précurseurs tardifs de la lignée érythroblastique, dont elle ne stimule cependant pas la division. En fait, des chercheurs de Nashville (TN, USA) viennent de montrer qu'en l'absence d'érythropoiétine des précurseurs érythroblastiques subissaient rapidement des phénomènes d'apoptose marqués par la fragmentation nucléaire. Les doses d'érythropoiétine permettant d'éviter au maximum la mort des précurseurs érythroïdes sont bien supérieures à celles mesurées in vivo dans des conditions normales. Il apparaît ainsi que l'érythropoï̀se est habituellement limitée par une considérable mortalité cellulaire. Une hyper-production d'érythropoïétine réduit cette mortalité et stimule de ce fait l'érythropoìèse. Ainsi la dimension des populations cellulaires apparaît-elle contrôlée à au moins trois niveaux : la stimulation de la prolifération par les facteurs de croissance ; la cessation de la prolifération, induite par des molécules dont le TGF- $\beta$ (transforming growth factor) et les interférons sont, au moins pour certains types cellulaires, des exemples ; la survie cellulaire, enfin, nécessitant la présence de facteurs trophiques. Existet-il aussi, physiologiquement, des substances dont le rôle serait d'induire électivement la mort de certaines populations de cellules ? On connaît déjà des exemples de destruction de cellules particulières

1. Berman P, Gray P, Chen E, et al. Sequence analysis cellular localization and expression of a neuroretina adhesion and cell survival molecule. Cell 1987 ; 51 : 135-42.

2. Lin LF, Mismer D, Lile J, et al. Purification, cloning and expression of ciliary neurotrophic factor (CNTF). Science 1989; 246 : 1023-5.

3. Leibrock J, Lottspeich F, Hohn A, et al. Molecular cloning and expression of brainderived neurotrophic factor. Nature 1989 ; 341 : 149-51.

4. Schubert D, Kimura $H$, La Corbière $M$, Vaughan J, Karr D, Fischer WH. Activin is a nerve cell survival molecule. Nature 1990 ; $344 ; 868-70$.

5. Koury MJ, Bondurant MC. Erythropoietin retards DNA breakdown and prevents programmed death in erythroid progenitor cells. Science 1990 : 248 : 378-81. à la suite de phénomènes d'interactions avec d'autres cellules; un mécanisme de mort spécifiquement déclenché est ainsi à la base des phénomènes d'acquisition de la tolérance immunologique par délétion clonale dans le thymus $(\mathrm{m} / \mathrm{s}$, suppl. au $n^{\circ} 1$, vol. 5, p. 25). Il est probable qu'existent aussi des hormones ou des agents à action paracrine capables de déclencher un programme de mort cellulaire au niveau de cibles particulières.

A.K. 